\title{
Jörn Rüsen e sua contribuição para a didática da História
}

\author{
Maria Auxiliadora Schmidt \\ Profa. e pesquisadora do programa de pós-graduação em Educação da Universidade Federal do Paraná \\ dolinha08@uol.com.br
}

Recebido em 17/02/2017. Aprovado em 31/03/2017.

Como citar este artigo: Schmidt, Maria Auxiliadora. "Jörn Rüsen e sua contribuição para a didática da História". Intelligere, Revista de História Intelectual, vol. 3, n², p. 60-76. 2017. Disponível em http://revistas.usp.br/revistaintelligere $>$. Acesso em dd $/ \mathrm{mm} /$ aaaa.

Resumo: A partir do recorte acerca da obra de Jörn Rüsen no que se refere à sua teoria da aprendizagem histórica, se propõe analisar as contribuições para a pesquisa e para a educação histórica. De um lado, a apropriação destas contribuições, tendo como referência e fundamentação a teoria da História, é algo a ser acolhido e anunciam um novo paradigma para a relação entre aprendizagem e ensino de História, o que se propõe a realizar na primeira parte deste trabalho. De outro, a partir destes pressupostos, foram tomadas como objeto de análise investigações que vem sendo realizadas no Brasil, na área do ensino de História, que têm como referência teórica o pensamento ruseniano. Resultados destas pesquisas, ainda que parciais, indicam várias questões a serem levadas em consideração, no que se refere à aprendizagem das crianças e jovens, seja em ambiente escolar ou outros ambientes de aprendizagem. Ademais, suscitam novas questões de investigação, que também serão apontadas neste trabalho.

Palavras-chave: Didática da História; Jörn Rüsen; Aprendizagem Histórica; Metodologia do Ensino de História; Educação Histórica.

\section{Jörn Rüsen and his contribution to didactics of History}

\begin{abstract}
The aim of this work is to evaluate contributions to research and historical education from a cutting of Jörn Rüsen's work about his theory of historical learning. From one side and for the first part of this work, the appropriation of these contributions is having as reference and substantiation the theory of History which should be approached that is an announcement of a new paradigm for the relationship between History learning and History teaching. On the other hand, following these presumptions investigations which have been developed in Brazil were taken as the object of analysis from History teaching subjects. These researches have the ruseniano thought as a theoretical reference. Preliminary results of these investigations indicate a series of questions that need to be taken in consideration regarding children and young adults learning either at the school environment or other learning spaces. In addition, they raise new questions that should be investigated which will be pointed in this work.
\end{abstract}


Keywords: Didactics of History; Jörn Rüsen; Historical Learning; History Teaching Methodology; History Education.

O conceito de Didática da História tem sido objeto de debates e reflexões, não somente no campo da História, mas também na Educação. Vários autores vêm contestando posições que pensam a Didática da História apenas como um conjunto de conhecimentos que tentam transformar, na prática, historiadores profissionais em professores da escola fundamental e média. Essa perspectiva tem acompanhado muitas concepções relacionadas com as disciplinas destinadas a ensinar como se ensina a história. ${ }^{1}$

Em termos gerais, constata-se a existência de um domínio teórico específico do conhecimento denominado Didática da História, o qual se inscreve nas interfaces da investigação entre a epistemologia da História, tomada como referência para a construção de categorias e metodologias de análise, e seu diálogo com outras ciências, situado "na encruzilhada de diversas ciências humanas entre as quais estão, por um lado, as que se ocupam tradicionalmente da aprendizagem e, por outro, as que constituem a base do conhecimento que se pretende ensinar". ${ }^{2}$ Assim, é possível pensar a reconstrução da disciplina Didática da História e, no Brasil, autores como Cardoso ${ }^{3}$ Cerri $^{4}$ e Saddi ${ }^{5}$ têm publicado reflexões acerca desta temática. Do ponto de vista da epistemologia da História, as reflexões de Jörn Rüsen ${ }^{6}$ acerca da Didática e funções do saber histórico, trazem o pressuposto da Didática como a ciência da aprendizagem histórica, bem como a assertiva de que "o ensinar e aprender história são da alçada de uma disciplina especializada, a didática da história. Essa disciplina se desenvolveu como campo acadêmico autônomo, com debates teóricos e métodos de pesquisa próprios, que não podem mais ser ignorados pela academia"7.

A centralidade da aprendizagem na prática docente é uma problemática que vem sendo enfrentada por educadores em geral e, especialmente, pelos especialistas na área das Didáticas Específicas, como a Didática da História, podendo-se afirmar que se sabemos como se aprende, pode-se saber como se ensina. Assim, entende-se que o "elemento nuclear da prática docente é a aprendizagem, que resulta da atividade intelectual e prática de quem aprende em relação ao conteúdo ou objeto, realizada junto com os professores e colegas. Portanto, a referência para as atividades de ensino é a aprendizagem do aluno; o como se ensina depende de saber como os indivíduos aprendem"». Ressalta-se, assim, a importância da concepção de aprendizagem como ponto de partida e pressuposto orientador do método de ensino da História, bem como a sua complexidade e diversidade de abordagens, tendo em vista a sua relação com a ciência de referência.

A aprendizagem histórica pressupõe a interiorização de novas qualidades cognitivas com o objeto que está sendo aprendido e, nesse sentido, algumas questões se apresentam.

${ }^{1}$ Levantamento realizado por Adriane Sobanski, como parte de tese de doutorado em desenvolvimento no PPGEUFPR-2015, constatou a existência, nas grades curriculares, de diferentes cursos de graduação em História do Brasil, de um conjunto de disciplinas relacionadas à temática de como ensinar história, tais como: Metodologia do Ensino de História, Didática da História, Prática de Ensino de História, Estágio Supervisionado em História e Oficina de Ensino de História.

2 Joaquim Prats, "Enseñar Historia: notas para uma didáctica renovada", Consejeria de Educacion, Ciencia y Tecnologia. Junta de Extremadura (Mérida), 2001.

${ }^{3}$ Oldimar Cardoso, "Para uma definição de Didática da História", Revista Brasileira de História, [vol.] 28, 55 (2008): (153170)

${ }^{4}$ Luis Fernando Cerri, "Didática da História: uma leitura teórica sobre a História como prática”, Revista de História Regional, [vol.]15, 2 (2010): (264-278)

${ }^{5}$ Rafael Saddi, "Didática da História como subdisciplina da ciência da História", Revista História \& Ensino, [vol.]16, 1 (2010).

${ }^{6}$ Jörn Rüsen, História Viva. Teoria da História III: formas e funções do conhecimento histórico (Brasília: Editora da Unb, 2007).

${ }^{7}$ Id., Teoria da História: Uma teoria da história como ciência (Curitiba: Editora da UFPR, 2015): 247.

${ }^{8}$ José Carlos Libâneo, "A integração entre a didática e a epistemologia das disciplinas: uma via para a renovação dos conteúdos da Didática”. In: Convergências e tensões no campo da formação e do trabalho docente: Didática e formação de professores, trabalho docente, ed. Ângela Dalben. (Belo Horizonte: Autêntica, 2010). 
Além da especificidade do objeto que está sendo aprendido, inquere-se, por exemplo: -que novas qualidades cognitivas seriam essas? E também - o que orienta a intencionalidade de quem ensina em relação a quem aprende e a de quem aprende em relação a quem ensina? Onde encontrar respostas para estas questões? Nas ciências da educação ou na própria História?

$\mathrm{Na}$ tentativa de responder às problemáticas, pode-se remeter ao diálogo com o pensamento de Jörn Rüsen, buscando-se fundamentação para uma teoria da aprendizagem, fundamentada na ciência da História e que seja orientadora do significado e função da aprendizagem histórica como o centro da Didática da História. Ao assumir o princípio da Didática da História como ciência da aprendizagem histórica, Rüsen justifica dizendo que isto ocorre porque "ela produz de modo científico (especializado) o conhecimento necessário e próprio à história, quando se necessita compreender os processos de aprendizagem e lidar com eles de modo competente" . Afirma também que "todo conhecimento acerca do que seja a aprendizagem histórica requer o conhecimento do que seja história, daquilo em que consiste a especificidade do pensamento histórico e da forma científica moderna em que se expressa. No cerne da questão está a capacidade de pensar historicamente, a ser desenvolvida nos processos de educação e formação"10. Depreende-se então, que na perspectiva ruseniana, a aprendizagem constitui a centralidade da Didática da História e que seus fundamentos estão na própria ciência da História, porque "a especificidade da aprendizagem histórica só pode ser entendida se forem também entendidos os respectivos processos e formas de lidar com a experiência do passado. Pois é somente por intermédio desses processos que o passado se torna história"11.

As reflexões de Jörn Rüsen, ao trazerem o pressuposto da Didática como a ciência da aprendizagem histórica, sinalizam que a questão central é compreender como o pensamento histórico contribui para orientar, temporalmente, a vida humana para dentro (identidade) e para fora (práxis). Do ponto de vista epistemológico, a Didática da História presta contas com o processo do aprender a pensar historicamente, ou seja, com realizar a "formação histórica" e isto envolve dois aspectos - vida prática e ciência - organicamente interligados. Numa perspectiva transversal, significa entender o saber histórico como síntese da experiência humana com a sua interpretação para orientação na vida prática; e na horizontal, seria considerar a formação como socialização e individuação (dinâmica da identidade histórica) a partir de sua relação com a ciência.

Neste ponto, Rüsen apresenta sua crítica ao que chamou "Didática da Cópia", ou seja, a forma pela qual foi e é realizada a transposição do saber histórico científico para a forma escolar, que resultou, entre outros, no banimento dos procedimentos científicos relacionados ao processo de produção do conhecimento histórico, tais como: a forma de geração de problemas históricos a partir das carências de orientação da vida prática; a relação entre a formatação histórica e o público e a função de orientação da vida prática como algo que influencia a própria produção do conhecimento histórico. Para o autor, o problema da Didática da História não reside na sua autonomia ou diferença em relação à ciência da História, mas no estatuto ou natureza desta relação, abrindo possibilidades para se levar em conta alguns princípios que seriam constitutivos da epistemologia da Didática da História, com implicações para a metodologia do ensino de história e para as pesquisas nesta área. Entre os princípios norteadores, podem ser citados: 1) O estatuto ou natureza da relação entre a História e a Didática da História; 2) A formação da consciência histórica como pressuposto e finalidade da aprendizagem histórica; 3) A narrativa como forma e função da aprendizagem histórica. 4.A aprendizagem histórica como apreensão da mudança temporal.

\footnotetext{
${ }^{9}$ Jörn Rüsen, Teoria da História: Uma teoria da história como ciência (Curitiba: Editora da UFPR, 2015), 248.

${ }^{10}$ Ibid., 249.

11 Ibid., 255
} 


\section{O estatuto ou a natureza da relação entre História e a Didática da História}

Em busca da aproximação entre a teoria da História e a Didática da História, Jörn Rüsen propôs uma matriz da Didática da História, tendo como referência a sua matriz do pensamento histórico. ${ }^{12}$

\section{MATRIZ DA DIDÁTICA DA HISTÓRIA}

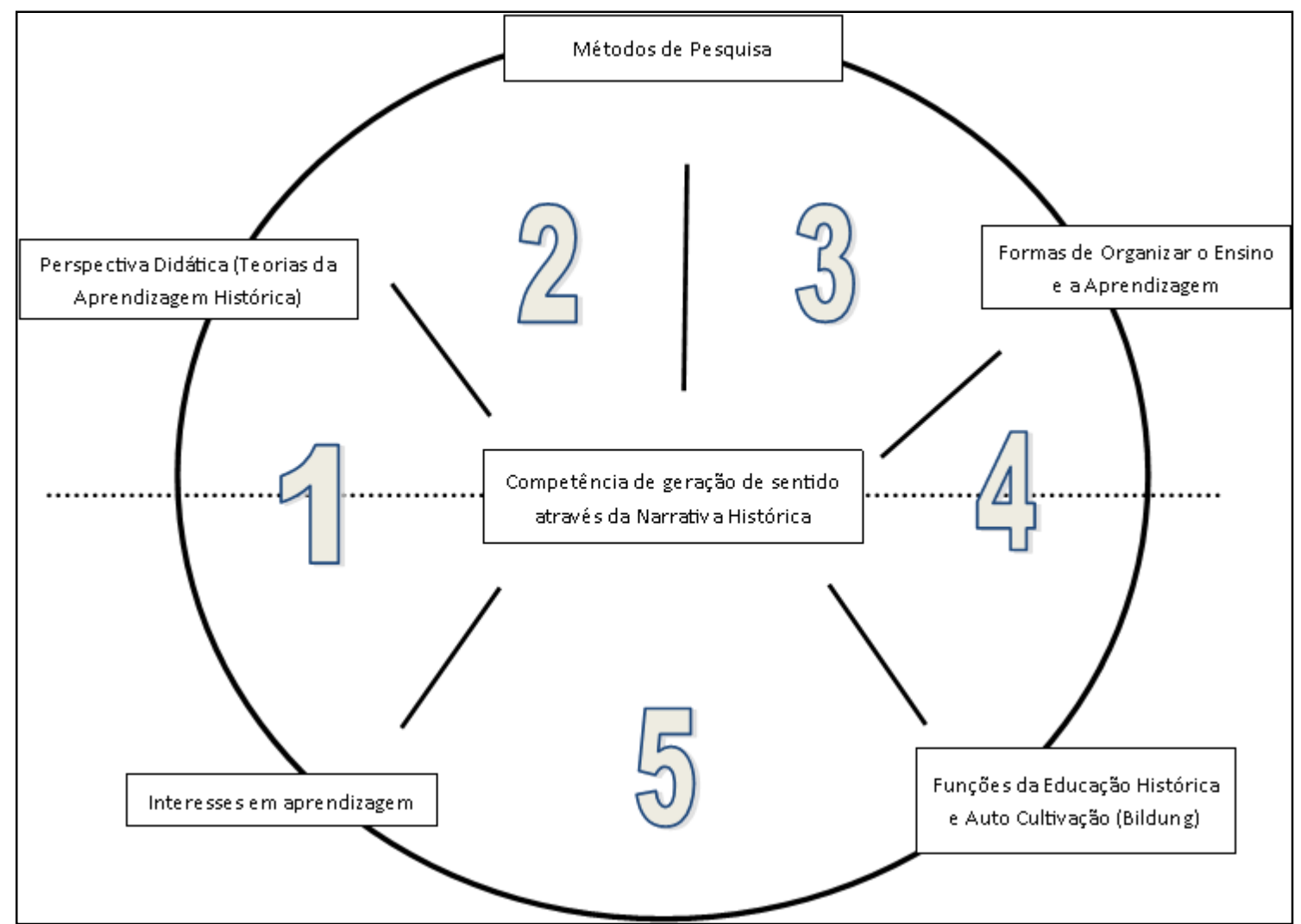

Fonte: RÜSEN, Jörn, 2016, p.25.

A matriz sugere a imprescindível relação entre a vida prática dos sujeitos - professores e alunos - e a ciência da história, quando se propõe um processo de ensino e aprendizagem, pois ela é o ponto de partida e de chegada do ensino de história, partindo das carências e interesses dos sujeitos, sempre relacionados ao mundo onde eles estão e poderão ser envolvidos. Estes interesses indicam a ida às teorias da aprendizagem, depositárias dos conceitos históricos, sejam eles substantivos (relacionados aos conteúdos da história), ou epistemológicos (relacionados aos processos cognitivos do pensamento histórico, tais como evidência e explicação histórica). O percurso em direção ao método da pesquisa pressupõe, entre outros, que na relação ensino e aprendizagem deve ser percorrido o mesmo processo constitutivo da produção do conhecimento histórico. Neste caso, por exemplo, o trabalho com fontes históricas torna-se fundamental como princípio do método de ensino. A educação bancária, ou seja, o método em que o aluno é mero depositário de conteúdos previamente selecionados, precisa ser definitivamente abandonada. As formas de organizar o ensino e a aprendizagem referem-se ao momento em que, tanto quem ensina, quanto quem aprende,

${ }^{12}$ Uma versão em português da Matriz do Pensamento Histórico de Jörn Rüsen pode ser encontrada no seu livro Teoria da História. Uma teoria da História como ciência (Curitiba: Editora da UFPR, 2015), 73, traduzido por Estevão C. de Rezende Martins. 
assumem o estatuto narrativístico da ciência da história. $O$ retorno à vida prática indica $o$ momento em que o conhecimento ensinado e aprendido revelam o significado e sentido de orientação temporal que têm para os envolvidos no processo de ensino e aprendizado: professores e alunos. Indica-se, aqui, o cerne da matriz ruseniana da Didática da História, o processo de construção de sentidos, a partir do conhecimento que produz o envolvimento dos sujeitos no seu próprio autoconhecimento, no conhecimento do outro e do mundo.

A matriz da Didática da História sugere uma relação orgânica entre a teoria da História e a própria Didática da História, particularmente no que diz respeito ao papel do conhecimento histórico científico. Tal relação indica ser imprescindível que o processo de ensino e aprendizagem da História precisa consultar a ciência de referência sobre as diversas formas e os diversos conteúdos pertinentes à aprendizagem, o que não é uma tarefa fácil, segundo o próprio Rüsen ${ }^{13}$, pois se corre o risco de subordinação e da funcionalização entre um e outro nesta relação. Como exemplo da subordinação da Didática a um tipo de conhecimento histórico pode ser citada a chamada Didática da Longa Duração, proposta pelo canadense André Ségal ${ }^{14}$. Tendo como referência o trabalho de Fernand Braudel, ele propõe um ensino de História a partir do conceito de fato histórico e das três ordens de duração: o acontecimento, a estrutura e a conjuntura.

O inverso também pode acontecer, quando a ciência da História e sua aprendizagem passam a ser regidos por princípios oriundos da Pedagogia, como a "pedagogia dos objetivos", cujo exemplo, no Brasil, pode ser encontrado na proposta de Neves ${ }^{15}$. A autora organiza o ensino e aprendizagemdos conteúdos da História a partir de objetivos operacionais, tais como caracterizar, enumerar, concluir, sintetizar, identificar e analisar.

\section{A formação da consciência histórica como pressuposto e finalidade da aprendizagem histórica}

Em diferentes obras já publicadas em português ${ }^{16}$, Jörn Rüsen tem mostrado que o trabalho com o conhecimento histórico na escola é fundamental para a formação da consciência histórica, ou seja, para o processo de interiorização das formas de organizar e dar sentidos às experiências temporais individuais e coletivas dos alunos. As experiências são importantes para a definição e inserção do sujeito em seu próprio destino. A "consciência histórica", para ele, é o modo pelo qual a relação dinâmica entre experiência do tempo e intenção no tempo se realiza no processo da vida humana. Assim, a História tem uma função didática de formar a consciência histórica, na perspectiva de fornecer elementos para uma orientação, interpretação (para dentro - apropriação de identidades, e para fora - fornecendo sentidos para ação na vida humana prática). Esses pressupostos podem ser referenciais para concepções de aprendizagem que orientem propostas curriculares de história na sociedade contemporânea, incorporando, também, o pressuposto inegociável de que qualquer aprendizagem é autoeducação e inseparável da prática significativa da auto-gestão, em que os jovens e crianças sejam agentes ativos de sua própria educação.

\footnotetext{
${ }^{13}$ Jörn Rüsen, História Viva. Teoria da História III: formas e funções do conbecimento histórico (Brasília: Editora da Unb, 2007). 14 André Ségal, "Pour une didactique de la durée". In: Enseigner l'histoire. Des manuels à la mémoire, Henri Moniot (Berne: Peter Lang, 1984).

${ }^{15}$ Maria Apparecida Mamede Neves, "Ensinando e Aprendendo História” (São Paulo: EPU, 1985).

${ }^{16}$ Entre as obras de referência, em que Jörn Rüsen aborda esta temática, publicadas em português, encontram-se: SCHMIDT, M.A./BARCA, I./ MARTINS, E.R. (ed.) Jörn Rüsen e o Ensino de História. Curitiba: Editora da UFPR, 2010; RÜSEN, Jörn. Aprendizagem Histórica. Fundamentos e Paradigmas. Curitiba: W \& A Editores, 2012; SCHMIDT, M.A./BARCA, I./ FRONZA, M./ NECHI, L. (ed.) Jörn Rüsen. Humanismo e Didática da História. Curitiba: W \& A Editores, 2015; RÜSEN, Jörn. Teoria da História. Uma teoria da História como ciência. Curitiba: Editora da UFPR, 2015; SCHMIDT, M.A./ MARTINS, E.R. (ed.) Jörn Rüsen. Contribuições para uma Teoria da Didática da História. Curitiba: W \& A Editores, 2016.
} 
Cabe enfatizar que, para Rüsen, não se pode restringir a aprendizagem histórica apenas à sua dimensão cognitiva. É importante levar em conta o significado extraordinário da dimensão "estética" da constituição histórica de sentido (e não apenas na era da nova mídia ou apenas entre crianças e jovens) que acaba por ser amiúde marginalizada, embora sua significação dificilmente poderia ser superestimada. Em comparação com essa situação, a dimensão "política" não fica de fora por uma razão evidente: o estado e a sociedade sempre tiveram interesse em tornar a cultura política profícua para o futuro, na sucessão das gerações, e de reforçar, com isso, os critérios determinantes da legitimação histórica do poder, e os processos históricos de escolarização têm contribuído para isto. Também as duas demais dimensões - a "moral" e a "religiosa" - possuem relevância para a Didática da História e carecem de análise de sua função didática, pela teoria da história. O autor destaca ainda três conteúdos principais da dimensão moral no que se refere à aprendizagem histórica: “(a) primeiro, o papel desempenhado pelo pensamento histórico na orientação cultural da vida humana prática; (b) o manejo distanciado e crítico do pensamento histórico, com pretensões normativas, que é construído na relação ensino-aprendizagem da História, no interior dos respectivos contextos sociais; (c) por fim, a hermenêutica do sentido normativo próprio do passado, distinguido do presente, de que decorre a historicização (e não a relativização) dos fundamentos normativos da vida prática contemporânea"17.

Ao se colocar a pergunta, "Então, o que é aprendizagem histórica?”, Rüsen reafirma sua posição de que se trata de um processo básico e fundamental que tem como referência a ciência da história e isso leva à mudança da Didática da História para a consciência histórica como base de todo o ensino e aprendizado da história, podendo-se associar e explicar a consciência histórica como teoria da aprendizagem histórica.

Esse referencial da experiência individual e social com o conhecimento admite a possibilidade de se falar da consciência histórica como lugar e propósito da aprendizagem, particularmente, como afirma Rüsen ${ }^{18}$, em dois aspectos: $O$ primeiro diz respeito à inclusão de aspectos da subjetividade de professores e alunos como processos de individualização e socialização em que a autocompreensão histórica afeta significativamente a identidade de cada um deles. O segundo, não menos importante, antevê a importância e significado do conhecimento histórico na sua vida prática.

Torna-se necessário compreender a consciência histórica como um processo mental, como um conjunto de operações da consciência (emocional, cognitivo e pragmático), que difere de outros conjuntos conceitualmente claros e que, em sua especificidade, podem ser explicitados. Esse processo mental se expressa, essencialmente, por meio da "narrativa histórica", que sintetiza as três dimensões do tempo na representação de um sentido global. "Continuidade" ou "decorrer do tempo" é a definição categórica desta determinação contínua fundamental, que combina o processo de formação histórica de significado da experiência temporal das três dimensões para a unidade de um sentido consistente de coerência, na comunicação social e auto compreensão humana, sendo importante forma de socialização e individualização. Ainda, segundo Rüsen, a consciência histórica pode ser utilizada para a formação da identidade histórica, pois, com ela, os sujeitos (individuais e coletivos) podem exceder os limites de seu tempo de vida, ao mesmo tempo colocá-los na mudança do tempo a que eles estão submetidos, e com isso, simultaneamente, ganhar uma subjetividade permanente. Nessa perspectiva, não há aprendizagem histórica se não houver uma apreensão de processos de apropriação da própria experiência, o que pressupõe uma educação calcada na experiência do tempo que ative, amplie e modifique significados acerca dessa experiência, por meio da narrativa histórica.

${ }^{17}$ Jörn Rüsen, Teoria da História: Uma teoria da história como ciência (Curitiba: Editora da UFPR, 2015), 158.

${ }^{18}$ Id., Aprendizagem Histórica: Fundamentos e Paradigmas (Curitiba: W \& A Editores, 2012). 
Ao dar centralidade à narratividade histórica como referência para o ensino e aprendizagem da História, Jörn Rüsen indica duas problemáticas a serem confrontadas. A primeira, diz respeito ao domínio da narrativa pelos professores em aulas de história e as tentativas de substituí-la por outras formas de comunicação. A segunda, é a própria teoria da narratividade da história que fundamenta a relação de dependência entre o ensino de história e a ciência da história.

\section{Narrativa como forma e função da aprendizagem histórica}

Se atentarmos para o processo de construção do "código disciplinar da História"19 no Brasil, a problemática da narrativa no ensino de História apresenta vários aspectos a serem analisados, tais como a presença da narrativa histórica à moda do século XIX em manuais e sua repercussão no ensino mnemônico; a influência do ensino tecnicista e seu correlato na chamada aprendizagem de marcar "X" em questões de múltipla escolha. Sem falar na especificidade de um tipo de "narrativa anônima" característica dos manuais didáticos que, muitas vezes, serve de referência para o conteúdo e a forma da aprendizagem nas aulas de História.

Concorda-se com Rüsen ${ }^{20}$ que contar histórias é uma conquista cultural vital que mostra a potencialidade do domínio da humanidade sobre o tempo passado, presente e futuro, bem como sua importância na intencionalidade da organização da vida prática. Isso significa a criação de significados e experiências temporais que definem o homem como espécie. Esses princípios levam à especificidade da narrativa histórica e da história como um conteúdo específico do pensamento, que é formado pelas três qualidades simbólicas da experiência temporal: a memória, a continuidade e a intencionalidade. Assim, torna-se compreensível que a aprendizagem histórica precisa reconhecer a consciência histórica como um processo, além de vê-la no seu próprio conteúdo.

Reconhecer a consciência histórica como um processo e a aprendizagem como narrativa, na esteira do pensamento de Rüsen, pressupõe admitir a importância de se fundamentar a aprendizagem nas atividades cognitivas do sujeito que aprende e com as quais todo o ensino da História deve se relacionar. Como indicam as considerações apropriadas da investigação de Gevaerd ${ }^{21}$, a Didática da História tem sido mais centrada numa aprendizagem da recepção de conteúdos previamente selecionados por parte dos professores, e não tem incorporado a tematização da experiência do sujeito que aprende, bem como o desenvolvimento de operações mentais próprias do pensamento histórico, que são necessárias para a elaboração de uma narrativa histórica.

Quais seriam as operações mentais que caracterizariam essa aprendizagem histórica? Nesse terreno, Rüsen ${ }^{22}$ estabelece contrapontos com autores alemães como Karl-Ernst Jeismann, que definiu essas operações como a análise, a avaliação e o julgamento, que ganhariam estatuto histórico ao se relacionarem com o assunto História. Também a proposta de Rolf Schörken é problematizada pelo autor, quando esse último afirma que o entendimento dos alunos sobre a história mundial pode ser passado, não só por meio de conteúdos, mas a partir de uma tomada de consciência estruturada de pensamento e processos que estão atrás dos conteúdos e, ao permanecerem ocultos no sujeito que aprende, seriam determinados por

${ }^{19}$ Raimundo Cuesta Fernandez, Sociogénesis de una disciplina escolar: la Historia (Barcelona: Ediciones Pomares-Corredor, 1998).

${ }^{20}$ Jörn Rüsen, Aprendizagem Histórica: Fundamentos e Paradigmas.

${ }^{21}$ Rosi T. Ferrarini Gevaerd, "A narrativa histórica como umamaneira de ensinar e aprender história: o caso da História do Paraná"

(Tese de doutorado, Universidade Federal do Paraná, 2009).

22 Jörn Rüsen, Aprendizagem Histórica: Fundamentos e Paradigmas (Curitiba: W \& A Editores, 2012). 
comportamentos relacionados à produção de identidades, lealdades e simpatias. No entender de Rüsen ${ }^{23}$, tanto as orientações de Jeismann quanto as de Schörcken, podem ser relevantes como operações da consciência histórica, quando aparecerem como fatores do processo de formação de sentido da narrativa histórica.

No entanto, mais do que isso, a aprendizagem deve ser baseada em formas de pensamento histórico elaboradas pelo sujeito que aprende, e é com essas formas de pensamento, organicamente ligados ao ato de narrar, que o ensino de História precisa se relacionar. Segundo estes pressupostos, a aprendizagem histórica ocorreria quando o sujeito desenvolvesse, por meio da narrativa histórica, um sentido para a experiência histórica, de tal forma que ele poderia orientar a sua existência em relação a si mesmo e aos outros, no fluxo do tempo. Nesse sentido, a perspectiva da aprendizagem somente pode se orientar na direção de que o sujeito é construtor do seu conhecimento.

Não se trata, segundo Rüsen²4, apenas da "implementação", "aplicação" ou "mediação" dos conteúdos sob a tutela dos objetivos ou competências de aprendizagem, mas do fato de que o próprio ensino e a História encontram seu sentido na vida prática humana. Assim, o conhecimento histórico e seus processos de aprendizagem passam a ter uma utilidade vital. Aprender história significa aprender a narrá-la, de tal forma que, nela e com ela, podemos encontrar o reconhecimento, sem o qual não gostaríamos de ser ou de poder ser. Ademais, o sentido da história não se reduz a uma autoafirmação compulsiva ou violenta com todas as consequências dolorosas para os envolvidos, mas, abre-se a um aumento permanente das experiências temporais que são processadas em um movimento contínuo, entre a experiência da diversidade do outro e a afirmação do eu. Esta abertura da consciência histórica pode ser apreendida pelo fato dos alunos terem recebido, quantitativamente e qualitativamente, diferentes interpretações temporais da experiência histórica, de modo que eles obtêm sua autonomia por meio de um ato de escolh

\section{A aprendizagem histórica como apreensão da mudança temporal}

O paradigma da aprendizagem histórica situada na teoria da consciência histórica proposto por Jörn Rüsen parte do princípio de que não existe compreensão histórica sem o entendimento da mudança temporal. No entanto, esse entendimento necessita ser construído tendo como referência a inserção do sujeito no presente e a partir de indagações históricas que possibilitem a significação desse mesmo presente, por meio do passado. Essa compreensão pressupõe, ainda, que o sujeito aprenda a estruturar a ideia de tempo cognitivamente, não somente do ponto de vista individual, mas, principalmente, relacionada à ideia de humanidade, pois "história é temporalizar a humanidade" 25.

Assim, a aprendizagem histórica só ocorre quando conseguimos processar a experiência da mudança temporal do mundo humano, produzindo o sentido histórico. Para que aconteça a aprendizagem histórica da produção de sentido histórico, a partir do processamento da experiência temporal, alguns desafios devem ser assumidos porque o processo de passar por essa experiência inclui as dimensões da interpretação, ou seja, o que se aprende tem que fazer um sentido para o aprendiz; - a orientação, isto é, o processo da mudança temporal precisa ser articulado "ao meu tempo, ao tempo do outro e ao tempo do outro que me inclui. Nesse caso, a questão principal seria - "como eu me coloco nesta situação de mudança temporal?" "26.

\footnotetext{
23 Ibid.

24 Ibid.

${ }^{25}$ Id., Contribuições para uma teoria da Didática da História (Curitiba: W \& A Editores, 2016).

${ }^{26}$ Ibid., 19.
} 
Outra dimensão é a da Motivação, em que o sujeito aprendiz necessita aprender a situar e inserir os seus objetivos de vida, tanto individuais, como coletivos, no fluxo do tempo.

As forças motrizes desses desafios indicam questões fundamentais para subsidiar os objetivos da aprendizagem histórica, tais como: o desafio da experiência histórica - o que eu percebi?; o desafio de compreender o passado alheio - o que isso significa?; o desafio da orientação da dimensão temporal de sua própria vida - onde é o meu lugar no tempo? e o desafio de escolher suas próprias motivações - o que eu posso fazer no futuro? Entre os resultados da aprendizagem pautada nesses pressupostos estariam a expansão quantitativa e qualitativa da capacidade de interpretar uma experiência histórica vivida, o aumento da competência de usar a experiência histórica vivida (conhecimento histórico) para temporalizar o seu próprio mundo e sua identidade, de conformar as aspirações individuais a partir de uma ideia empiricamente plausível de mudança temporal do curso da humanidade no tempo e de motivar os outros a realizarem suas próprias experiências de acordo com a ideia do lugar de cada um e do seu lugar no processo de mudança no tempo ${ }^{27}$.

\section{Implicações para a metodologia do ensino de História}

A necessidade de a aprendizagem histórica ser baseada em múltiplas perspectivas e narrativas ${ }^{28}$ é um dos princípios que devem conduzir o processo de ensino e aprendizagem na organização das aulas de História. Desse ponto de vista, Jörn Rüsen não aceita que a história seja "contada pelos outros" (o professor) e as competências narrativas dos alunos sejam consideradas como objetivos pedagógicos antecipados e tomadas como estratégias de adaptação funcional dos conteúdos. Para ele, a autoatividade do aluno é fundamental para que ele opere sua identidade de uma forma discursiva argumentativa, necessária à orientação temporal.

É nessa direção que o princípio metodológico da multiperspectividade nas aulas de história deve ser reconhecido como essencial, significando que as experiências históricas precisam ser de tal forma apresentadas, que causem uma identificação com o envolvimento dos alunos, a partir da divergência entre os diferentes pontos de vista. Segundo Rüsen ${ }^{29}$ na prática do ensino de história, a subjetividade do aluno deixa, na transformação da experiência que lhe diz respeito (e isso também quer dizer: objetivo), duas maneiras de aparecer: (a) a primeira é indireta, por meio de uma identificação com aqueles que foram sujeitos pelo desenvolvimento temático histórico; (b) a outra, diretamente, por meio da reflexão dos próprios pontos de vista, na reconstrução do desenvolvimento histórico. Assim, a aula de história não deve e não pode evitar uma participação prévia, com a qual os alunos trazem seus próprios pontos de vista e sua perspectiva da interpretação histórica.

A proposição de uma metodologia do ensino que tem como referência a formação da consciência histórica, não se trata, segundo Rüsen ${ }^{30}$, apenas da "implementação", "aplicação" ou "mediação" dos conteúdos sob a tutela dos objetivos ou competências de aprendizagem, mas do fato de que o próprio ensino e a História encontram seu sentido na vida prática humana. Assim, o conhecimento histórico e seus processos de aprendizagem passam a ter uma utilidade vital. Isso porque, a aprendizagem histórica deve levar a um sentido de compromisso histórico, onde se percebe que, na função de orientação, o que está em jogo na identidade própria do aluno, é a interação com os outros. Um princípio metodológico fundamental é que ensinar História significa contribuir para que o aluno aprenda narrar a história, de tal forma que, nela e com ela, pode encontrar o reconhecimento, sem o qual não gostaria de ser ou de

\footnotetext{
${ }^{27}$ Jörn Rüsen, Aprendizagem Histórica: Fundamentos e Paradigmas (Curitiba: W \& A Editores, 2012).

28 Ibid.

29 Ibid.

${ }^{30}$ Jörn Rüsen, Aprendizagem Histórica: Fundamentos e Paradigmas (Curitiba: W \& A Editores, 2012).
} 
poder ser. Ademais, quem ensina tem que interiorizar o princípio de que o sentido da história não se reduz a uma autoafirmação compulsiva ou violenta com todas as consequências dolorosas para os envolvidos, mas, abre-se a um aumento permanente das experiências temporais que são processadas em um movimento contínuo, entre a experiência da diversidade do outro e a afirmação do eu. Esta abertura da consciência histórica pode ser apreendida pelo fato dos alunos receberem diferentes interpretações da experiência histórica, de modo que eles obtêm sua autonomia por meio de um ato de escolha.

A matriz da Didática da História de Jörn Rüsen foi tomada como referência para uma proposta de metodologia do ensino e incluída nas Diretrizes Curriculares para o Ensino de História da Rede Municipal de Ensino de Curitiba, Paraná, com a denominação de "Aula Histórica" 31

\section{METODOLOGIA DA AULA HISTÓRICA}

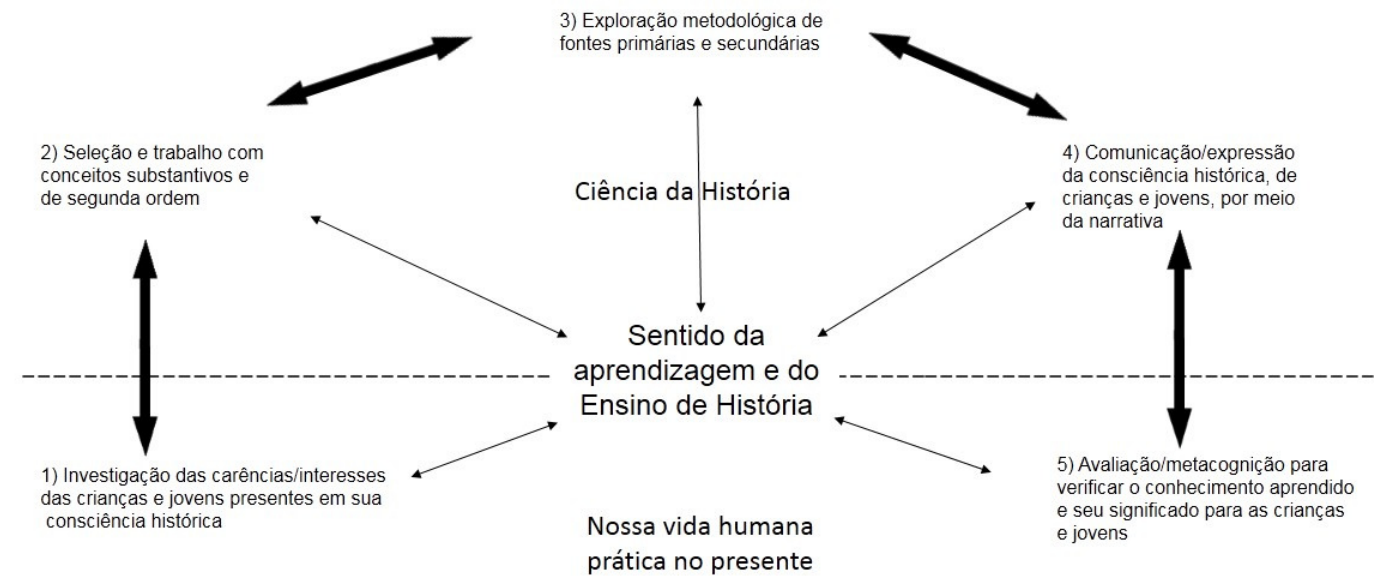

Fonte: Matriz da Didática da História de JÖRN RÜSEN (2016, p 25.).

Adaptado por SCHMIDT, M. A. In: CURITIBA/SMED, 2016.

A proposta da Aula-Histórica estrutura-se a partir de um processo que obedece a determinados fatores e que, na prática da aula de história, ocorrem de forma interdependentes:

1) Considerando que toda criança e jovem dispõe de uma consciência histórica, a partir do modo como dá sentido à sua experiência no tempo, é fundamental investigar as carências de orientação na sua vida prática e os interesses que esses sujeitos expressam ao iniciar o trabalho com um novo conteúdo da História; 
2) Após as crianças e jovens expressarem suas carências e interesses em relação ao novo conteúdo da História, o(a) professor(a) seleciona os conceitos substantivos e de segunda ordem a serem trabalhados, tendo como ponto de partida essas carências temporais e interesses;

3) Considerando os procedimentos adotados pelo historiador na produção do conhecimento histórico, o(a) professor(a) organiza metodologicamente a sua prática docente a partir do trabalho com fontes históricas - primárias e secundárias, problematizando-as e interpelando-as, permitindo às crianças e jovens interpretarem e problematizarem esses vestígios do passado à luz de sua vida prática no presente;

4) Após o(a) professor(a) orientar o trabalho da produção do conhecimento histórico, as crianças e jovens produzem narrativas que expressam as suas consciências históricas a partir de interpretações e problematizações que surgem no trabalho com as fontes. Importante ressaltar que a referência às fontes e uso de marcadores temporais podem ser considerados importantes indícios de que a narrativa das crianças e jovens tem uma natureza histórica;

5) A avaliação contínua e a sistematização da avaliação, a partir da perspectiva da metacognição (o que os sujeitos sabem acerca do que eles aprenderam), fazem com que as crianças e jovens percebam o seu próprio processo de aprender. A compreensão dos processos mobilizados desde a investigação das carências e dos interesses desses sujeitos até a produção de uma narrativa que expressa sua consciência histórica, permite que as crianças e os jovens tomem consciência dos seus processos cognitivos, atribuindo significados e conferindo sentidos ao que aprendeu ${ }^{32}$.

\section{Implicações para as pesquisas sobre ensino de História}

A mudança de paradigma trouxe importantes consequências para o desenvolvimento de pesquisas no ensino de História. Ao indicar a consciência histórica como lugar da aprendizagem, colocou novas questões do ponto de vista conceitual e de elaboração teórica. Para Jörn Rüsen ${ }^{33}$, isto requer investigações empíricas, ao tempo em que demanda uma operacionalização nas perspectivas Heurística, Analítica e Interpretativa. Do ponto de vista da Heurística, significa que uma teoria da aprendizagem necessita investigações que levem em conta os enunciados da consciência histórica que identificam e tornam possíveis (do ponto de vista teórico), os desempenhos da aprendizagem histórica (como ela se manifesta?). A perspectiva Analítica indica que uma teoria da aprendizagem fornece os critérios e categorias necessários às investigações do conteúdo material dos ditos enunciados (por exemplo, a categoria da multiperspectividade). Finalmente, a perspectiva Interpretativa parte de uma teoria da aprendizagem que possibilita a formação de hipóteses de investigações sobre as correlações empíricas entre os diferentes fatores e desenvolvimento da consciência histórica, e as condições em que ocorrem tais correlações.

Esse novo paradigma da aprendizagem histórica considera que a consciência histórica se revela, principalmente, na e pela linguagem. Assim, os enunciados linguísticos puderam ser privilegiados como interesses de pesquisa, mas não somente eles, porque outros elementos, como os símbolos imagéticos, também são indicativos da expressividade dos sentidos da interpretação do tempo e, portanto, reveladores da consciência histórica. Novas e importantes

${ }^{32}$ Curitiba/Smed- Secretaria Municipal de Educação, Diretrizes Curriculares do Ensino Fundamental - História. Proposta. 2016.

33 Jörn Rüsen, Aprendizagem Histórica: Fundamentos e Paradigmas (Curitiba: W \& A Editores, 2012). 
problemáticas de investigação têm sido postuladas. Questões como: como relacionar as diferentes fases da vida (infância, juventude), como a forma dos seus modelos de interpretação histórica? Seriam os modelos de interpretação histórica influenciados pelos conteúdos, até o ponto de provocarem alterações em sua interpretação? Os modelos de interpretação dependem, e, em caso positivo, em que grau, dependem das visões de mundo e da ética dos aprendizes? A capacidade de utilizar modelos de interpretação mais complexos e elaborados na apreensão da experiência histórica diminui ou aumenta, na medida em que os conteúdos da experiência tangenciam questões pessoais imediatas dos sujeitos, ou contestam autoafirmações e/ou pontos de vista profundamente enraizados? ${ }^{34}$.

Partindo do pressuposto básico de que a consciência histórica é o lugar da aprendizagem, as investigações têm tido a preocupação com questões como as que envolvem a definição, a conceituação, a elaboração, investigar as funções, abordar as condições, forças motrizes e consequências das ideias históricas presentes na cultura escolar, seja nas ideias de professores e alunos, seja em outros lugares da cultura escolar, como os manuais didáticos e currículos. Para efeito de exemplificação, foram selecionadas duas investigações realizadas em cursos de doutorado, sendo uma de Portugal e uma do Brasil.

As pesquisas que tomam os referenciais da teoria de Jörn Rüsen como suportes teóricos e metodológicos para analisar a aprendizagem histórica de crianças, jovens e professores, se autodenominam pesquisas em "cognição histórica", constituindo, hoje, o campo ou domínio científico de investigação chamado "Educação Histórica". Neste campo, as dimensões e elementos relacionados com a natureza da ciência da História e suas articulações com a aprendizagem e, portanto, o ensino da História, têm sido o objeto e a finalidade das investigações. Segundo Gago ${ }^{35}$, os trabalhos do historiador e pesquisador inglês Peter Lee, por exemplo, colaboraram no sentido de apontar que a aprendizagem histórica lida com a apropriação dos conceitos substantivos da História, tais como "Revolução Industrial Inglesa", bem como os conceitos meta históricos, ou seja - "os conceitos meta históricos (ou de natureza histórica) são os conceitos inerentes à própria História-ciência que estão sempre presentes quando se estuda História porque lhe dão corpo. Conceitos como evidência, explicação histórica, que se articulam com a narrativa histórica"36.

Em sua pesquisa - Consciência histórica e narrativa na aula de história: concep̧̧̃oes de professores ${ }^{37}$ a historiadora e investigadora portuguesa Marilia Gago tomou como referência a categoria da narrativa histórica, para definir seu objeto e os objetivos de sua investigação de doutorado, realizada sob a orientação da profa Dra. Isabel Barca, na Universidade do Minho, Portugal. Realizada em escolas de diferentes regiões de Portugal, investigou uma população de 36 professores e 12 estudantes de cursos de História deste país.

Logo de início, anuncia e debate o quadro teórico em que construiu a sua investigação, define os objetivos e articula as questões a serem elucidadas. Partindo da relação entre narrativa e consciência histórica, seleciona e visita autores do campo da teoria e filosofia da história, evidenciando as relações entre narrativa histórica, tempo, memória e consciência histórica.

Este ponto de partida fez com que a pesquisadora assumisse o pressuposto de que o uso da narrativa na aula de História não se limite à aquisição, por parte do professor e, portanto, por parte dos alunos, de "histórias" sobre o passado. Ao contrário, anuncia, como

\footnotetext{
34 Ibid, 94-102.

35 Marilia Gago, Pluralidade de olhares: Construtivismo e Multiperspectiva no processo de aprendizagem (Moçambique, EPM/CELP, 2012), 60-86.

${ }^{36}$ Ibid., 30.

${ }^{37}$ Marilia Gago, “Consciência histórica e narrativa na aula de história: concep̣cões de profesores” (Tese de doutorado, Universidade do Minho. Instituto de Educação e Psicologia, 2007).
} 
necessária, a construção, por parte de ambos, de suas próprias narrativas, "de um passado interpretado historicamente, com sentido para suas próprias vidas"38.

Para compreender estes quadros conceituais, à luz da questão de investigação, ela revisita vários autores, para discutir o conceito de narrativa histórica e consciência histórica, partindo do debate existente no interior da epistemologia da história, o "narrativeturn". Procura mostrar o que chamou de "tensão do debate", entre os polos em torno da narrativa e da realidade histórica: os polos objetivista, realista, empiricista e os polos subjetivista, relativista e representacionista. À luz do debate entre autores de filosofia da história, discute os diferentes conceitos de narrativa histórica para subsidiar um conceito de narrativa histórica que foi orientador de sua investigação, ou seja - A narrativa como forma de expressão do passado humano experimentado diferentemente, de acordo como determinados campos de referência e descrição, que subsidiam uma forma de compreensão explicativa-descritiva que compreende a orientação temporal. Trata-se de uma concepção que pressupõe o realismo interno e objetividade perspectivada, baseada na interpretação da evidência, existindo um compromisso com o distanciamento, justiça e honestidade intelectual. Entende a narrativa como experiência de significação e modo de expressão de sentido, plural e múltipla em termos argumentativos, procurando no criticismo aberto e mútuo uma compreensão mais relevante, mais aceitável e mais coerente racionalmente, que forma e enforma a identidade histórica.

A partir da categoria mestra narrativa histórica, e os significados que lhe são atribuídos, a autora vai ao encontro das ideias de Jörn Rüsen de que as formas da consciência histórica podem se expressar narrativamente e "conjugando o empírico e o normativo, surge como uma matriz de premissas baseadas no sentido construído das ações do passado que orientam o presente e permitem perscrutar diferentes horizontes de expectativas futuras" 39 . Tendo como referência este quadro teórico, propõe o objetivo da investigação: Compreender as concepções de professores de História acerca da narrativa enquanto uma das faces da consciência histórica, bem como as suas questões de investigação: Que perfis conceituais revelam os professores e futuros professores de História acerca da narrativa nas suas relações com a consciência histórica? Que relações terão esses perfis conceituais com a experiência profissional e a faixa etária dos professores e futuros professores? ${ }^{40}$.

Observa-se a preocupação da pesquisadora com a aprendizagem relacionada à formação da consciência histórica e o lugar do desenvolvimento da competência narrativa nesta formação. Esta apreensão do processo de aprendizagem histórica de professores e futuros professores pode ser considerada uma aderência à ideia de cognição histórica e, portanto, da aprendizagem histórica, fundamentada na teoria de Jörn Rüsen.

A segunda pesquisa, indiciária da apropriação do pensamento ruseniano, é do historiador Ronaldo Cardoso Alves. Trata-se da tese de doutorado - Aprender História com sentido para a vida: consciência histórica em estudantes brasileiros e portugueses - defendida em 2011 na Universidade de São Paulo, sob a orientação da profa. Dra. Kátia Abud.

O ponto de partida da pesquisa é a preocupação do investigador com a relação entre ensino de história e seu significado para a vida prática dos alunos, instigando a seguinte questão - "será que, ao estudarmos história em espaços escolares ou extra escolares, conseguimos perceber a relação que ela tem com a nossa vida?”.

\footnotetext{
${ }^{38}$ Ibid., 13.

${ }^{39}$ Ibid.

${ }^{40}$ Ibid., 74.
} 
Reporta-se a Jörn Rüsen, para assumir o pressuposto de que há uma relação orgânica entre a construção do conhecimento histórico e a necessidade de orientação dos seres humanos em seu cotidiano. Nesta direção, aponta duas questões:

1) Que parâmetros metodológicos podem dotar a história de plausibilidade e fiabilidade para as questões do cotidiano?

2) Como possibilitar às novas gerações habilidades e competências cognitivas oriundas da ciência da História, que proporcionem sentido às decisões da vida prática?

Assim, referencia-se em Rüsen ${ }^{41}$ para relacionar conhecimento histórico e vida prática, por meio do raciocínio histórico que dota os seres humanos de instrumentos cognitivos estruturados, com a finalidade de enfrentar, conscientemente, a rotineira tomada de decisões, demandada de uma cultura histórica na qual ocorre a multiplicidade e diversidade de informações. Ao lançar a pergunta - para que serve a história? - o autor defende o "desenvolvimento da consciência histórica" como finalidade do ensino de história e sua utilização na vida cotidiana.

Toma como referência também a produção investigativa anglo-saxônica, representada, principalmente, por historiadores da Universidade de Londres, como Peter Lee, Denis Shemilt, Rosalyn Ashby, apresentando em seus trabalhos evidência de uma mudança de paradigma nos referenciais teóricos da pesquisa sobre aprendizagem histórica. Estes autores, tendo como base a filosofia e a teoria da História anglo-saxã, estabeleceram categorias fundadoras do pensamento histórico, ao tempo em que, a partir de suas investigações, indicam níveis diferenciados de compreensão, explicação e interpretação das fontes históricas pelos alunos.

A leitura realizada por Alves ${ }^{42}$, seja da teoria ruseniana, seja dos fundamentos teóricos das investigações anglo-saxãs, o leva a estabelecer uma diferenciação entre os pressupostos dos diferentes pesquisadores. $\mathrm{Na}$ Alemanha, segundo ele, as relações entre a filosofia e a teoria da história tomam como ponto de partida a racionalidade histórica estruturada no espaço escolar, que relaciona a aprendizagem histórica às carências da vida prática, com a finalidade da formação histórica. Os ingleses tomam a vivência escolar como ponto de partida para o desenvolvimento do conhecimento histórico, mediado por uma reflexão epistemológica que propicie aos professores e alunos o desenvolvimento de competências para uma literacia histórica. Isto é, a constituição de práticas metodológicas que visem desenvolver operações mentais do pensamento histórico - substantivo (aplicação dos conteúdos/conceitos históricos na vida prática) e metahistóricos - instrumentos cognitivos utilizados para raciocinar historicamente. Ele se apropria da perspectiva anglo saxã também a partir de Barca ${ }^{43}$, para desenvolver a ideia de "opinião fundamentada" como possibilidade de apropriação cognitiva do real.

Em Jörn Rüsen encontra os fundamentos para justificar a formação da consciência histórica a partir da relação com a vida prática e sua possibilidade de aplicação no contexto latino-americano, uma necessidade de pensar uma consciência histórica dialógica, devido presença de grandes diferenças sociais nos países da América Latina. Relaciona consciência histórica com o conceito de cultura histórica de Rüsen para justificar a importância do desenvolvimento e qualificação das operações mentais do pensamento histórico. E coloca a

\footnotetext{
${ }^{41}$ Jörn Rüsen, Razão Histórica. Teoria da história: os fundamentos da ciência histórica. (Brasília: Editora da UnB, 2001).

${ }^{42}$ Ronaldo Cardoso Alves, "Aprender história com sentido para a vida: consciência bistórica em estudantes brasileiros e portugueses" (Tese de doutorado, Universidade de São Paulo, 2011).

${ }^{43}$ Isabel Barca, "Literacia e consciência histórica", Revista Educar. Dossiê Especial: Educação Histórica, (2006)(193-211).
} 
seguinte pergunta: "Como o pensamento histórico pode atuar na relação dos seres humanos com a cultura histórica?".

A partir da questão, propõe um estudo comparativo entre jovens brasileiros e portugueses, para discutir a formação do pensamento histórico no âmbito escolar e sua aplicação como consciência histórica na vida prática, a partir do encontro entre a Didática da História e a Educação Histórica, levantando indagações: Como se forma o pensamento histórico? Como este pensamento é aplicado no cotidiano? Há possibilidade de demonstrar, empiricamente, tipos ou níveis de consciência histórica que representem diferentes formas de geração de sentidos para as ações na vida prática? Existem semelhanças e diferenças na utilização do pensamento histórico, por parte de estudantes de diferentes grupos sócioeconômicos ou sociais? Qual a contribuição da escola nesse processo de formação do pensamento histórico e, principalmente, da consciência histórica dos estudantes?

Sistematizando sua adesão ao pensamento ruseniano, o autor elabora a questão final de investigação: Em que medida o pensamento histórico de jovens brasileiros e portugueses apresenta aspectos de uma consciência histórica adequada para reflexão a respeito da cultura histórica contemporânea?

\section{Considerações finais}

Os atuais programas governamentais para o ensino de História, tais como os Parâmetros Curriculares Nacionais e a proposta da Base Curricular Nacional Comum, revelam a maneira pela qual tem ocorrido, no Brasil, a separação entre a Didática da História e a História acadêmica, contribuindo para a formação de um código disciplinar da História com características específicas em cada momento da sociedade brasileira, mas que, de modo geral, empurrou as questões do ensino e aprendizagem da História tendencialmente para o âmbito da cultura escolar, especialmente para as relações com determinadas teorias pedagógicas, como a pedagogia das competências. Foi a partir desse reajustamento que a dimensão cognitiva do ensino da História passou a se articular com a dimensão política da cultura histórica. Nesse processo, as questões relacionadas à aprendizagem histórica e, portanto, ao seu ensino, saíram da pauta dos historiadores e entraram, prioritariamente, na pauta das políticas educacionais, ocorrendo um deslocamento entre a cultura histórica e a cultura escolar, em que a perspectiva instrumental, particularmente centralizada na preocupação com a transposição didática e com os métodos de ensino por competências e habilidades, tem sido privilegiada.

As contribuições teóricas de Jörn Rüsen indicam várias questões a serem levadas em consideração no que se refere à aprendizagem das crianças e jovens, seja em ambiente escolar ou outros ambientes de aprendizagem, como museus e arquivos. Entre elas a de que, definitivamente, os professores de história precisam saber que devem abandonar o pressuposto de que aprender história significa acumular conhecimentos, mesmo que adotando metodologias ativas e lúdicas e que aprender história não é manter-se no nível do senso comum ou adquirir bom senso a respeito das questões do passado.

A partir das investigações já realizadas pelos diferentes grupos, fundamentadas em pressupostos desta teoria, principalmente no fato de que a consciência histórica é ponto de partida e de chegada da aprendizagem histórica, o historiador inglês Peter Lee ${ }^{44}$ propôs o conceito de Literacia Histórica, tendo como referência a ideia de que aprender história significa transformar informações em conhecimentos, apropriando-se das ideias históricas de forma

${ }^{44}$ Peter Lee, "Em direção a um conceito de literacia histórica", Revista Educar. Dossiê Especial Educação Histórica, (Curitiba: Editora da UFPR, 2006). 
cada vez mais complexa. O conceito de literacia histórica entende que a finalidade do ensino de História é levar à população os conteúdos, temas, métodos, procedimentos e técnicas que o historiador utiliza para produzir o conhecimento histórico, ressalvando que não se trata de transformar todas as pessoas em historiadores, mas de ensinar a pensar historicamente.

A literacia histórica tem como finalidade a aprendizagem para a formação da consciência histórica mais complexa. Isto significa que o ensino de história deve ter por objetivo a formação de uma consciência histórica que supere formas tradicionais e exemplares da consciência histórica, responsáveis pela consolidação de narrativas baseadas em organizações lineares do tempo, bem como as visões de que a história é a mestra da vida. Ao mesmo tempo, busca-se também evitar a formação de consciências críticas pautadas em narrativas que rompem com qualquer possibilidade de rever o passado. O objetivo é uma consciência crítico-genética, onde a relação presente e passado seja fundamentada em narrativas mais complexas, que se prestem à uma orientação temporal para a vida presente, baseadas em alguns princípios como a liberdade, democracia e direitos humanos. A formação da consciência histórica, finalidade principal do ensino de História, leva em consideração que tanto os professores, como os alunos, fazem parte de um coletivo e de um tempo social. As investigações de Alves $^{45}$ e as de $\mathrm{Gago}^{46}$ são indiciárias de que as três dimensões da aprendizagem histórica, sugeridas por Rüsen ${ }^{47}$ - Experiência, Interpretação e Orientação estão sempre intimamente relacionadas, pois não existe experiência histórica sem significado ou orientação histórica sem experiência, o que implica em algumas consequências. Uma delas é o fato de que nunca se pode dissociar a aprendizagem histórica do sujeito que aprende, por exemplo, o jovem e a cultura jovem e, portanto, a dinâmica da aprendizagem não se realiza quando a história é ensinada como algo dado e alheio ao sujeito que aprende. Assim, saber história não é a mesma coisa que pensar historicamente correto, pois o conhecimento histórico que é apenas apreendido como algo dado, não desenvolve a capacidade de dar significados para a história e orientar aquele que aprende de acordo com a própria experiência histórica.

Questões como estas remetem a duas tendências presentes, atualmente, no ensino e aprendizagem da História. A primeira, a partir das apropriações que o inglês de Peter Lee fez da teoria de Jörn Rüsen, aponta a necessidade de se qualificar a aprendizagem histórica a partir do conceito de História Transformativa, isto é, levar em consideração o conjunto de questões que dizem respeito à preocupação de que, em que medida e em que aspectos a aprendizagem histórica e, portanto, o ensino de História, transforma a maneira com que os alunos são capazes de ver o mundo em que vivem. Neste sentido, seria importante manter perguntas como: Até que ponto o conhecimento histórico muda as ideias dos estudantes sobre as respostas adequadas para os problemas diplomáticos, políticos, econômicos, ambientais e culturais atuais? E, quanto tempo estas mudanças podem durar?

A segunda, nas trilhas do pensamento ruseniano, aponta para a importância de se pensar a formação da consciência histórica na perspectiva de uma didática humanista da história, pois "O trabalho da didática da história não pode ser entendido ou desenvolvido sem uma consciência de seu papel na cultura histórica de seu tempo. Ele tem de perceber e de responder aos desafios da orientação histórica, especialmente no que diz respeito ao aprendizado histórico e sua realização em diferentes instituições, principalmente na escola" ${ }^{48}$. Tais pressupostos instigam novas temáticas a serem debatidas, como o próprio significado que o novo paradigma da aprendizagem histórica trás para a Didática da História, seu escopo teórico, natureza e dimensões. Tais estudos demandam, por exemplo, análises comparativas

\footnotetext{
45 Ronaldo Cardoso Alves, "Aprender história com sentido para a vida: consciência histórica em estudantes brasileiros e portugueses"(Tese de doutorado, Universidade de São Paulo, 2011).

${ }^{46}$ Marilia Gago, "Consciência histórica e narrativa na aula de história: concepções de profesores" (Tese de doutorado, Universidade do Minho. Instituto de Educação e Psicologia, 2007).

${ }^{47}$ Jörn Rüsen, Aprendizagem Histórica: Fundamentos e Paradigmas.

${ }^{48}$ Jörn Rüsen, Teoria da História: Uma teoria da história como ciência (Curitiba: Editora da UFPR, 2015), 19.
} 
acerca da construção do código disciplinar ${ }^{49}$ da Didática da História em diferentes países e momentos históricos, bem como suas interfaces com questões contemporâneas, por exemplo, na perspectiva do "Novo Humanismo" de Jörn Rüsen.

Finalmente, algumas questões relevantes foram suscitadas pela difusão e apropriação do novo paradigma, que exigem um olhar atento e cuidadoso. Uma delas é a existência de propostas que sugerem a subordinação da aprendizagem histórica à formação para a cidadania. Em alguns países, há uma tendência em construir processos de fusão entre o ensino de história e a educação para a cidadania ou educação cívica. Parte-se do pressuposto de que o conhecimento histórico pode ser um suporte para a coesão social e/ou para ressurgimentos nacionais, seja em nome da diversidade ou da pressão da imigração, levando à busca da constituição de uma gama de valores comuns da história nacional. Outra tendência é a transformação do desenvolvimento do pensamento histórico e da formação da consciência histórica em desenvolvimento de competências. O contexto da globalização, da emergência competitiva de alguns países, da expansão dos mercados, desenvolveu uma tendência de simplificação das propostas curriculares "em um esforço para assegurar que as competências exigidas pelas empresas podem encontrar espaço na escola. Apesar de falar de uma economia do conhecimento, a pressão sobre o currículo parece ser para as escolas treinarem mão de obra eficaz" 50 . Neste sentido, abre-se espaço nos currículos para integração da história em humanidades e a justificativa para isto, geralmente é feita pelo apelo à "eficiência" em um mundo competitivo, mas também pode evocar condescendência sobre o que os alunos se interessam, podem lidar ou podem necessitar de autonomia e desenvolvimento pessoal, "os últimos argumentos por vezes evidenciam hostilidade às "disciplinas escolares" 51 .

Em acordo com Rüsen ${ }^{52}$, importa que a aprendizagem histórica desenvolva a capacidade de se adquirir a constituição narrativa de sentido, como uma aprendizagem de resignificar, continuamente, as experiências temporais da vida prática, desenvolvendo, de forma complexa e científica, a cognição propriamente histórica. Concorda-se, também, com este autor, que se trata de um processo da consciência histórica e como ele é apreendido e efetivado, não é uma questão da didática da teoria da História, mas da Didática da História uma disciplina da ciência da História, mas relativamente independente da teoria da História. Neste e para este processo, se direcionam as investigações acerca da aprendizagem histórica.

Há, portanto, a necessidade de consolidação da Didática da História, em que os conhecimentos necessários à produção do pensamento histórico sejam articulados a um projeto de educação pensado na perspectiva da insegurança da identidade histórica, das pressões relacionadas à diversidade cultural, das críticas ao pensamento ocidental e de uma nova relação com a natureza e com o outro, pois essa relação é fundamental para a compreensão do mundo. Uma necessidade que precisa ser articulada a um sentimento de urgência de se pensar para além dos embates herdados da separação entre a Didática da História e a História acadêmica.

\footnotetext{
${ }^{49}$ Raimundo Cuesta Fernandez, Sociogénesis de una disciplina escolar: la Historia (Barcelona: Ediciones Pomares-Corredor, 1998).

${ }^{50}$ Peter Lee, "Literacia Histórica e História Transformativa”, Revista Educar, n.60: (2016): 2 (107-146).

${ }^{51}$ Ibid., 3.

52 Jörn Rüsen, Aprendizagem Histórica: Fundamentos e Paradigmas.
} 